\title{
Effect Of ZnO Nanoparticles on the Physical, Chemical and Nutritional Quality of Tomato Plant (Solanum Lycopersicum)
}

\author{
Gul Muhammad ${ }^{1}$, Shahid Mehmood ${ }^{2}$, Rana Zafar Abbas Manj ${ }^{3}$, Sajid Mahmood ${ }^{4}$, Noor Hassan ${ }^{5 *}$ \\ and Muhammad Ashfaq Ali ${ }^{6}$ \\ ${ }^{1}$ Department of physics, Agriculture University of faisalabad, Pakistan
}

${ }^{2}$ Key Laboratory of Protein and Peptide Pharmaceuticals, Institute of Biophysics, Chinese Academy of Sciences, P.R. China

3State Key Laboratory for Modification of Chemical Fibers and Polymer Materials, College of Materials Science and Engineering, Donghua University, China

${ }^{4}$ Key Laboratory of the Ministry of Education for Advanced Catalysis Materials, Department of Chemistry, Zhejiang Normal University, China

${ }^{5}$ College of Chemistry and Life Sciences, Zhejiang Normal University, China

${ }^{6}$ Department of chemistry, Quaid-e-Azam University, Islamabad

*Corresponding author: Noor Hassan, College of Chemistry and Life Sciences, Zhejiang Normal University, Jinhua 321004, China

\section{ARTICLE INFO}

Received: 慧 October 25, 2021

Published: 慧 November 02, 2021

Citation: Gul Muhammad, Shahid Mehmood, Rana Zafar Abbas Manj, Sajid Mahmood, Noor Hassan, et al., Effect Of ZnO Nanoparticles on the Physical, Chemical and Nutritional Quality of Tomato Plant (Solanum Lycopersicum). Biomed J Sci \& Tech Res 39(5)-2021. BJSTR. MS.ID.006351.

\author{
ABSTRACT
}

The significance of horticulture to every single human culture is portrayed as never before, with the expanding total populace. Nanotechnology has been characterized as identifying with materials, frameworks, and procedures which work on a size of 100 nanometers or less. Nanotechnology has numerous applications in all phases of creation, handling, putting away, bundling and transport of agrarian items. The phytotoxic conduct of the nanoparticles should be tended to logically before using them for agribusiness rehearses. It will be trusted that the controlled arrival of dynamic plant development stimulators and different chemicals typified in Nano composites made of layered twofold hydroxides could be an achievable alternative to natural farming. Take-up of nanoparticles by plants, their translocation, and impact on plants will be accounted for. In this study, the impact of $\mathrm{ZnO}$ nanoparticles on seed germination and root development of the tomato (Solanum lycopersicum) will be researched and the treated gatherings will be contrasted with control bunches all together with screen positive or toxic impact. The leaf physical parameters like root length, shoot length and its external territory will be noted.

Keywords: Solanum Lycopersicum; ZnO Nanoparticles; Seed Germination; Root Development

\section{Introduction}

Food techniques were basically progressed in the forms of smart distribution of minerals, bio-separation of proteins, quick examining of ecological and chemical pollutants, nanoencapsulation of Nutraceuticals, solubilization, distribution, and color in feeding methods; these being few of the developing texts of nanotechnology in meal and farming [1]. Meanwhile, food nanotechnology as a recent technology was needing surveys of potential of the many positive results also has the negative results. In this view, we designed to cover a few of the developments in nanotechnology and their application to food and Nutraceutical's 
mechanisms. It presents a few of the Nanoscale-sized structures that are particularly related to the food products, the various food production methods that were assisting from nanotechnology, and nanotechnologies used for the preparation and keeping of food, collected by recognizing the great challenge [2-4]. Zinc is the required proteins for plant generation. It is also the major structure of ribosome and is ecessary for their growth.

Zinc is the dynamic component in biochemical methods and have a chemical and a biological interface with several more components [5]. Phosphorus is the one of the main components which disturbs on zinc absorb by plants. Phosphorus is the main components that disturbs with zinc absorb, as zinc absorb by plants decreases by rising phosphorus in loam. High levels of phosphorus may decrease the availability of zinc or the onset of zinc deficiency associated with phosphorus fertilization may be due to plant physiological factors. More strengths of copper in the mud results, apply to zinc, be able to shrink the accessibility of zinc to a plant in view of rival for the similar places of interest in the plant stem. It would take place once the use of a copper as fertilizer. Zinc scarcity is due to iron $(\mathrm{Fe})$ insufficiency, due to inhibit of a move to iron from root to shoot at the zinc insufficient situation. Acceptable quantity of zinc in the plant recovers the injurious causes of boron (B) scarcity. Zinc scarcity reduces plant growth by raising the strength of boron in the tips and the fresh leaves of the parts [6,7].

The study and progress in the area of nanotechnology are increasing quickly everywhere on the earth. The main part of that field is the improvement of newly substances on the nanoscale. In the area of nanotechnology, the particles can be measured at zero dimension, i.e., in quantum dots and in one dimension the particles are approximately less than 100 nanometers (nm). The several physical and chemical techniques are applied for the nanoparticle's synthesis. The elements generally used are poisonous, flammable, not simply disposed towards the ecological problems, having low products rate, and so on by applying these kinds of harmful methods. The rate of reducing metal ions using plants is formed to be much quicker as compared with the microorganisms and the stable forming of metal nanoparticles [8,9]. These particles are applied in several consumer products, and it is predicted that these NPs will enter into different ecosystems, where their actions are not recognized.

As a result, the organisms which are interactive with NPs are supposed to, that's an advantage or negative issue. The relations between microorganisms and the metals are well known and the ability of micro-organisms to extricate and/or assemble metals is once applied in biotechnological techniques such as bioleaching and bioremediation [10]. With the sudden increase in the using of engineered nanoparticles (NPs) that can be applied in many fields like pharmaceuticals, cosmetic products, energy industry and in machines [11-15]. At present observation nano toxicity is accepting increased, it is considered that engineered nanoparticles can be discharged to the atmosphere, mistakenly or indifferently. Regardless of the detail that more and more investigators are briefed the nanotoxicity in plants, the studies require at the rest of the rising phase and information on the results of nanoparticles in plant structures require for more analysis, especially in crop plants, given that the engineered nanoparticles may be a risk to people's condition for the group of food. These nanoparticles are distributed into four classes as carbon-based materials, metal-based materials, and complexes.

The metal oxide nanoparticles and all the metal-based materials playing an important role that is generally applied in monitor to atmospheric viruses, self-cleaning and catalysis [16-19]. Different types of metal oxide NPs are useful in farming, particularly used for the protection plant and germinate. Silicon dioxide nanoparticles can be applied for the happening of control release transported in narcotic method and as a mobile component in opposition to worms' pests, zinc oxide nanoparticles are used as pesticides. Absolutely, several metal oxide NPs are described to include positive causes on crop vegetation. For the case sprayed of $\mathrm{TiO} 2$ can considerably enhance the production of spinach, stem height of green peas considered by $\mathrm{ZnO}$ on soil is roughly two stages higher than the limitation. However, many of the investigators are describing the phytotoxicity of metal oxide nanoparticles in crop vegetative stage.

In that situation, it can be observed that differing conclusions (positive responses or negative responses) can be drawn about a similar metal oxide nanoparticle in various plants. By adding, the toxicity in crop plants is normally evaluated by applying one or two types of metal oxide NPs. Thus, it is vital to thoroughly examine the phytotoxicity of a wide group of metal oxide NPs in crop plants $[8,9]$. Dye Sensitized Solar Cells on its basis for various explicit band-gap semiconductors will be produced as well as designed though obtaining preferred outputs but growing conveyer cycles had great effects. By comparison with normal chips, a quadruped figure for zinc oxide will establish the important interest into the Dye Sensitized Solar Cells whereas their background structure of an interlinked quadruped structure gives better tracks through its transporters which move once that rearrange therefore controlling for the development conveyer cycles.

Other research group manufactured the Dye Sensitized Solar Cells on the basis of $30 \mathrm{~mm}$ broad layer upon its interlinked zinc oxide quadruped structure from a conducted surface and considered their routine. These dimensions established like the zinc oxide quadruped structure bases of Dye Sensitized Solar Cells will attain its performance that should be moreover upon this Dye Sensitized Solar Cells bases on zinc oxide nanowire displays or circular zinc oxide nanoparticles attain $[6,20]$. This thought 
is the portion of the evolved discipline of accuracy in farming, in which farmers build the use of technical to regularly use irrigate, nourishment, and other benefits. Chemical substances are applied to the growth of plant and fruit with the help of fertilizers. Spinach (Spinacia oleracea L.) is one commonly used green leafy vegetable eaten up in Pakistan. Spinach consists of a high nutritional rate of other vitamins i.e., vitamin $\mathrm{A}$, vitamin $\mathrm{C}$, vitamin $\mathrm{K}$, iron, folate, magnesium and manganese and it is the best resource of the nutrient fiber, potassium, calcium, vitamin $B$, vitamin $E$ and riboflavin. The main purpose of this present analysis is to yield a nanoparticles fertilizer supply on the nutrient use in productivity of spinach plant [21-24].

\section{Materials and Methods}

Solanum lycopersicum seeds in this experiment will be taken from the Ayub research centre, University of Agriculture, Faisalabad. ZnO nanoparticle will be used in sowing of these seeds in pots. The synthesized nanoparticles ( $\mathrm{ZnO}$ ) were used for treating fresh Solanum lycopersicum seeds in different concentrations [25]. Equal quantity of soil and equal amount of water will be added in pots. Treatment group will be compared with the control group. The plant parameters like root length, shoot length, shoot dry and fresh weight will be monitored. The number of treated samples and controlled sample will be monitored daily. The different growth parameter will be monitored and calculated in order to examine any positive or toxic effect of nanoparticles for the Solanum lycopersicum plant.

\section{Results and Discussion}

The pure zinc oxide powder was manufactured by chemical process named co-precipitation method by using Zinc Nitrate. Sodium hydroxide was used to maintain the $\mathrm{pH}$ of the solution, it was maintained at value 11 . Throughout the process of adding mixture, composites of zinc were prepared, and zinc ions totally dissolved in the solution. X-ray powder diffractometer patterns of zinc oxide samples were recorded using $\mathrm{Cu}$-Ka radiation $(=1.540598 \mathrm{~A})$ with 2 theta range from 20 to 80 To identify the peaks and phase transformations, the XRD pattern of zinc oxide sample is described in (Figure 1), together along with their appropriate XRD data (d-spacing, $2 \theta$ values, half maximum intensity, and relative intensity) Table 1. Debye Scherer's formula has been used to measure the crystalline size of all the specimens, and miller indices were also used to estimate the lattice parameters [26].

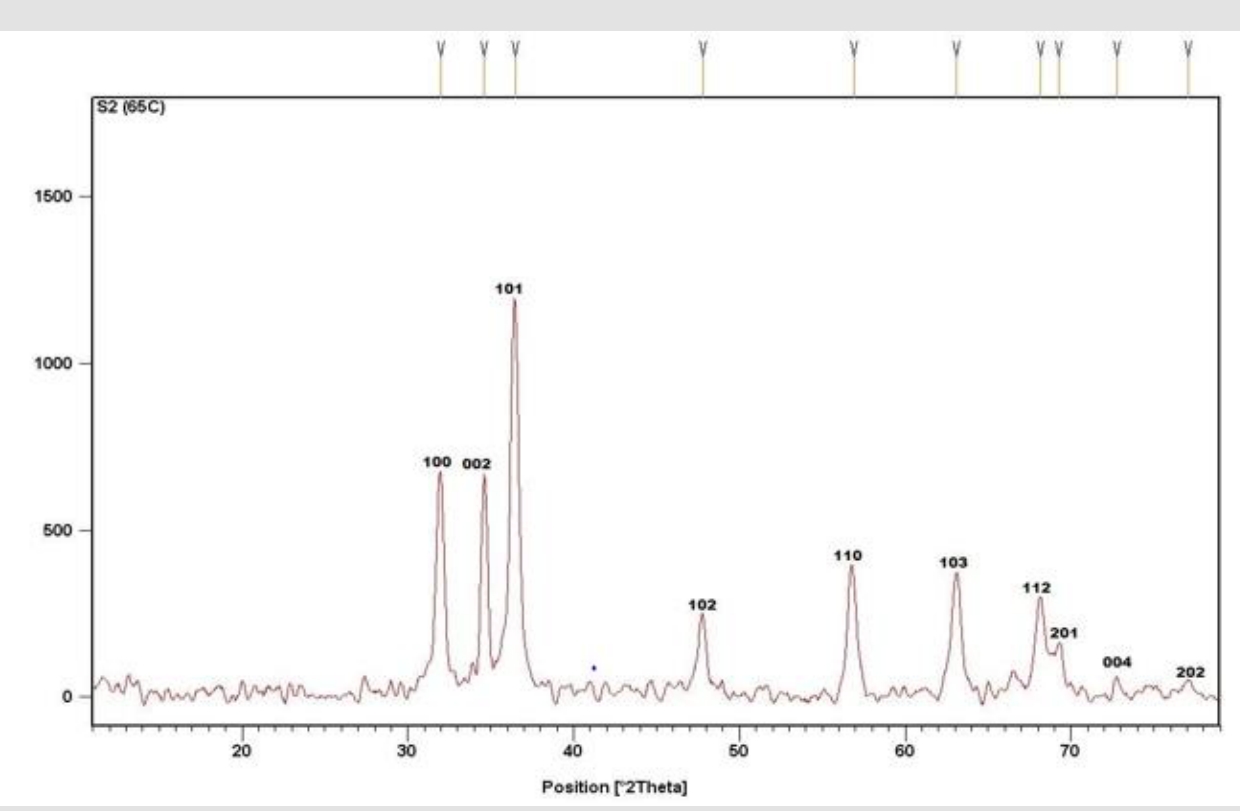

Figure 1: XRD pattern of $\mathrm{ZnO}$.

Table 1: Peak analysis of sample.

\begin{tabular}{|c|c|c|c|c|}
\hline Sr No. & $\mathbf{2} \theta$ (degree) & d-spacing [̊̊] & FWHM [o2Th] & Rel. Int. [\%] \\
\hline 01 & 32.1025 & 2.7999 & 0.2402 & 56.98 \\
\hline 02 & 33.9998 & 2.6001 & 0.1299 & 55.99 \\
\hline 03 & 36.9991 & 2.5021 & 0.3201 & 99.99 \\
\hline 04 & 48.0132 & 1.88989 & 0.2402 & 20.98 \\
\hline 05 & 57.1009 & 1.70113 & 0.2698 & 38.04 \\
\hline
\end{tabular}




\begin{tabular}{|l|c|c|c|c|}
\hline 06 & 63.2131 & 1.50202 & 0.4012 & 27.98 \\
\hline 07 & 67.9899 & 1.40125 & 0.4001 & 23.99 \\
\hline 08 & 70.0321 & 1.29887 & 0.3213 & 13.04 \\
\hline 09 & 76.9995 & 1.19998 & 1.149 & 5.01 \\
\hline
\end{tabular}

\section{Lattice Parameter}

The following equation help out to measure the lattice parameter and miller indices (hkl).

$$
\alpha=\frac{\lambda}{\sqrt{3 \sin \theta}} \sqrt{h^{2}+h k+l^{2}}
$$

$$
c=\frac{\lambda}{2 \sin \theta} l
$$

In this equation $\lambda$, explained wavelength of $x$-rays while its values are $1.540598 \AA$ on the other hand and c shows the lattice parameter and its value of sample in the (Table 2).

Table 2: Volume of unit cell of $\mathrm{ZnO}$ nanoparticles.

\begin{tabular}{|c|c|c|c|c|}
\hline Sr. No. & Sodium hydroxide (NaOH) & $\begin{array}{c}\text { Thermal treatment } \\
\text { Temperature (K) }\end{array}$ & Crystal points 'a' & Crystal points 'c' \\
\hline Analyte zinc oxide $(\mathrm{ZnO})$ & $3.9(\mathrm{~g})$ & $333 \mathrm{~K}$ & 3.99 & 5.100 \\
\hline
\end{tabular}

\section{Volume of Unit Cell}

Using the formula, calculate the volume of hexagonal wurtzite unit cells of $\mathrm{ZnO}$

$$
V=\frac{\sqrt{3}}{2} a^{2} c
$$

The lattice parameters are 'a' and 'c.' (Table 3)

Table 3: Volume of unit cell of $\mathrm{ZnO}$ nanoparticles.

\begin{tabular}{|c|c|c|c|}
\hline Sr. No & $\begin{array}{c}\text { Sodium } \\
\text { hydroxide } \\
\text { (NaOH) }\end{array}$ & $\begin{array}{c}\text { Thermal } \\
\text { treatment } \\
\text { Temperature (K) }\end{array}$ & $\begin{array}{c}\text { Unit Cell } \\
\text { (Volume) }\end{array}$ \\
\hline Sample ZnO & $4 \mathrm{~g}$ & $333 \mathrm{~K}$ & 68.55 \\
\hline
\end{tabular}

\section{Density of Unit Cell}

The density of a unit cell is defined as ratio of own mass to its own volume. The formula is used to determine it.

$$
p x=\frac{Z M}{Z A V}
$$

Where $\mathrm{Z}$ is the number of molecules per unit cell, $\mathrm{M}$ is the sample's molar mass, NA is Avogadro's number, and V is the unit cell's volume. The density of a unit cell is determined by measuring the amount of the unit cell and the sample's molar mass (Table 4).

Table 4: Density of unit cell of $\mathrm{ZnO}$ nanoparticles.

\begin{tabular}{|c|c|c|c|}
\hline Serial No. & $\mathbf{N a O H}$ & $\begin{array}{c}\text { Electric Oven } \\
\text { Temperature }(\mathbf{K})\end{array}$ & $\begin{array}{c}\text { Density } \mathbf{( g /} \\
\mathbf{c m}^{\mathbf{3}} \text { ) }\end{array}$ \\
\hline Sample ZnO & $4 \mathrm{~g}$ & $333 \mathrm{~K}$ & 7.49 \\
\hline
\end{tabular}

\section{Concentration Level of Magnesium in Solanum lycopersicum}

This graph shows the effect of Bulk, Nano and Control groups of the spinach leaves as using $\mathrm{ZnO}$ nanoparticles (Figures 1 \& 2). By adding $\mathrm{ZnO}$ the concentration level of magnesium in control group gradually increased as compared to other groups [27] (Figure 3).

\section{Concentration Level of Iron in Solanum Lycopersicum}

This graph shows the effect of Bulk, Nano and Control groups of the tomato leaves as using $\mathrm{ZnO}$ nanoparticles. By adding $\mathrm{ZnO}$ the concentration level of iron in control group gradually increased as compared to other groups [28] (Figure 4). 


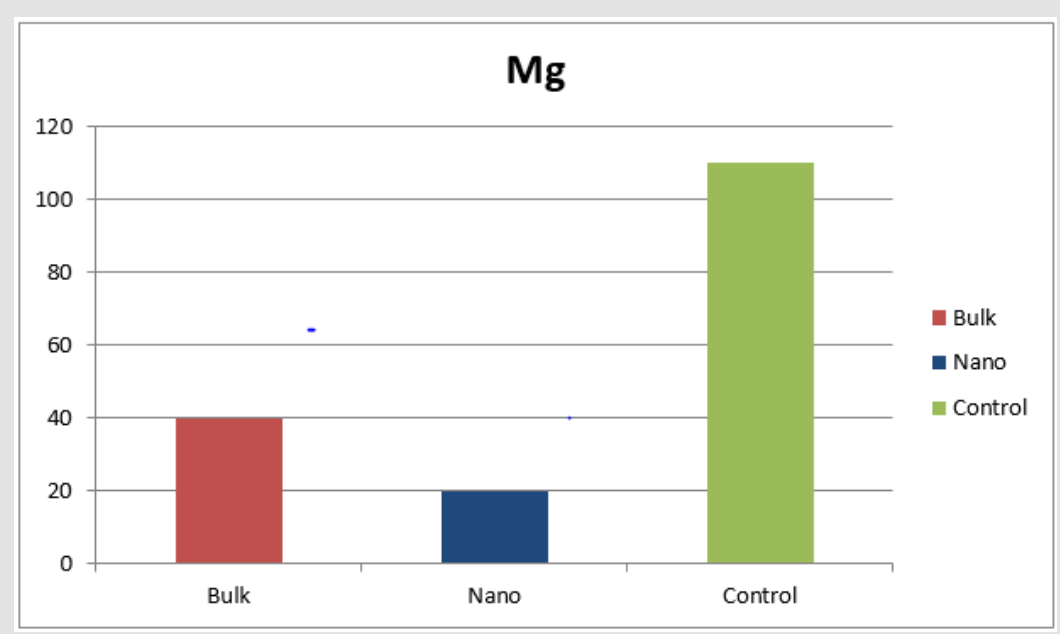

Figure 2: Concentration level of Magnesium in Solanum lycopersicum.

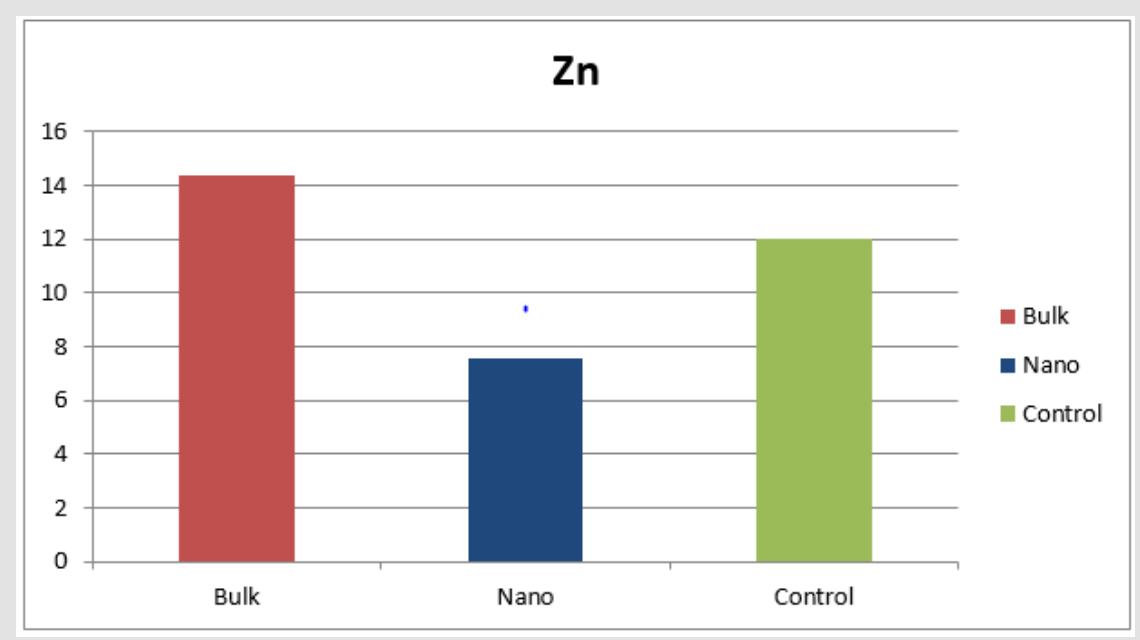

Figure 3: Concentration level of Zinc in Solanum lycopersicum.

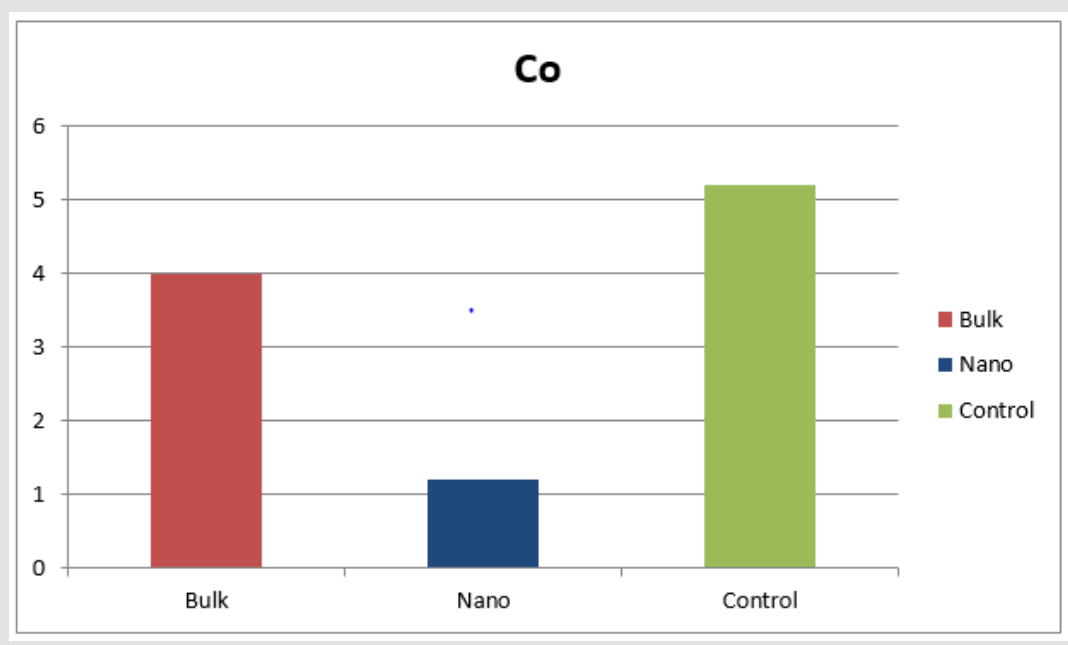

Figure 4: Concentration level of Cobalt in Solanum lycopersicum. 


\section{Concentration Level of Cobalt in Solanum Lycopersicum}

This graph shows the effect of Bulk, Nano and Control groups of the tomato leaves as using $\mathrm{ZnO}$ nanoparticles. By adding $\mathrm{ZnO}$ the concentration level of cobalt in control group gradually increased as compared to other groups [29-31].

\section{Conclusion}

The co-precipitation method was used to obtain the $\mathrm{ZnO}$ nanoparticle. Zinc oxide specimens have prepared by using the solution, Zinc Nitrate and sodium hydroxide solution having different ratios. The $\mathrm{pH}$ was maintained to the value 11 . For further process furnace treatment $400{ }^{\circ} \mathrm{C}$ for two hours is given to that powder to make comparison between the obtained nanoparticles from the oven. Scherrer's formula was used to calculate the crystal size of the material. All of the specimens' $x$-ray diffraction patterns were very comparable to the new patterns. The size of the produced particles was determined using Scherrer's formula. The Debye's formula was used for the lattice constants zinc oxide showed precisely same peaks as of the pure zinc oxide. Peak thickness and concentrations were varied. Their lattice constants varied significantly, but their ratio remained stagnant.

\section{References}

1. Bilal M, Mehmood S, Iqbal HM (2019) Immobilized enzyme-based biocatalytic cues: an effective approach to tackle industrial effluent waste. In Microbes for Sustainable Development and Bioremediation, pp. 287-311.

2. Al Tayyar NA, Youssef AM (2020) Antimicrobial packaging efficiency of $\mathrm{ZnO}_{-} \mathrm{SiO}_{2}$ nanocomposites infused into PVA/CS film for enhancing the shelf life of food products. Food Packaging and Shelf Life 25: 100523.

3. Kim I, Viswanathan K, Kasi G, Thanakkasaranee S, Sadeghi K, et al. (2020) $\mathrm{ZnO}$ nanostructures in active antibacterial food packaging: Preparation methods, antimicrobial mechanisms, safety issues, future prospects, and challenges. FOOD REVIEWS INTERNATIONAL, p. 1-29.

4. Sun J, Jiang $\mathrm{H}, \mathrm{Wu} \mathrm{H}$, Tong C, Pang J, et al. (2020) Multifunctional bionanocomposite films based on konjac glucomannan/chitosan with nano-ZnO and mulberry anthocyanin extract for active food packaging. PubAg 107: 105942.

5. Bilal M, Mehmood S, Rasheed T, Iqbal H (2019) Bio-catalysis and biomedical perspectives of magnetic nanoparticles as versatile carriers. Magnetochemistry 5(3): 42.

6. Khan M, Sabir M, Mustafa GM, Fatima M, Mahmood A, et al. (2020) 300 $\mathrm{keV}$ cobalt ions irradiations effect on the structural, morphological, optical and photovolatic properties of $\mathrm{Zn}$ doped $\mathrm{TiO} 2$ thin films-based dye sensitized solar cells 46(10): 16813-16819.

7. Rehman WU, Wang H, Manj RZA, Luo W, Yang JJS (2021) When Silicon Materials Meet Natural Sources: Opportunities and Challenges for LowCost Lithium Storage 17(9): 1904508.

8. Bian F, Zhong Z, Zhang X, Yang C, Gai X (2020) Bamboo-An untapped plant resource for the phytoremediation of heavy metal contaminated soils. Bioremediation 246: 125750.

9. Chen H, Yang X, Wang H, Sarkar B, Shaheen SM, et al. (2020) Animal carcass-and wood-derived biochars improved nutrient bioavailability, enzyme activity, and plant growth in metal-phthalic acid ester cocontaminated soils: A trial for reclamation and improvement of degraded soils. J Environ Manage 261: 110246.
10. Bilal M, Rasheed T, Mehmood S, Tang H, Ferreira L, et al. (2020) Mitigation of environmentally-related hazardous pollutants from water matrices using nanostructured materials-A review. Chemosphere 253: 126770.

11. Hussain A, Usman M, Manj RZA, Liu F, Li D, et al. (2021) Rational Design of Graphene-based Sorbents for Water Purification. In Nanostructured Catalysts for Environmental Applications, pp. 309-329.

12. Manj RZA, Chen X, Rehman WU, Zhu G, Luo W, et al. (2018) Big potential from silicon-based porous nanomaterials: in field of energy storage and sensors. Front Chem 6: 539

13. Manj RZA, Zhang F, Rehman WU, Luo W (2020) Toward understanding the interaction within Silicon-based anodes for stable lithium storage 385: 123821 .

14. Rehman WU, Zhang F, Manj RZA, Ma Y, Yang JJ (2021) Corncob derived porous carbon anode for long-term cycling in low-cost lithium storage. J o E E C\& Storage 19(1): 010909.

15. Yang W, Cheng P, Adams CA, Zhang S, Sun Y, et al. (2021) Effects of microplastics on plant growth and arbuscular mycorrhizal fungal communities in a soil spiked with ZnO nanoparticles. Biochemistry 155: 108179 .

16. Hassan N, Lu S, Xu W, Ge H, Naseer MA, et al. (2021) Fabrication of Pd nanoparticles on $\mathrm{Al}$ substrate with excellent superhydrophobicity and photocatalytic activity. Journal of Physics and Chemistry of Solids 148: 109704

17. Hassan N, Lu S, Xu W, Ge H, Sultana A, et al. (2021) Fabrication of stable superhydrophobic bismuth material on the aluminum substrate with high photocatalytic activity. Journal of Physics and Chemistry of Solids 23(4): 1-15

18. Hassan N, Lu S, Xu W, He G, Faheem M, et al. (2019) Fabrication of a Pt nanoparticle surface on an aluminum substrate to achieve excellent superhydrophobicity and catalytic activity. New Journal of Chemistry 43(15): 6069-6079.

19. Hassan N, Lu S, Xu W, Yu T, He G, et al. (2018) Fabrication of Ag-Fe304/Fe superhydrophobic surface on galvanic sheet for its application. Journal of Solid-State Chemistry 266: 121-132.

20. Ezhov AV, Aleksandrov AE, Zhdanova KA, Zhdanov AP, Klyukin IN, et al (2020) Synthesis of Zn (II) porphyrin dyes and revealing an influence of their alkyl substituents on performance of dye-sensitized solar cells 269: 116567

21. Adetola OY, Onabanjo OO (2020) The search for sustainable solutions: Producing a sweet potato based complementary food rich in vitamin A, Zinc and Iron for infants in developing countries. Stark AHJSA 8: e00363.

22. Alexander J, Tinkov A, Strand TA, Alehagen U, Skalny A, et al. (2020) Early nutritional interventions with zinc, selenium and vitamin D for raising anti-viral resistance against progressive COVID-19. Nutrients 12(8): 2358.

23. De Grande A, Ducatelle R, Delezie E, Rapp C, De Smet, et al. (2021) Effect of vitamin $\mathrm{E}$ level and dietary zinc source on performance and intestinal health parameters in male broilers exposed to a temperature challenge in the finisher period. J Anim Physiol Anim Nutr (Berl) 105(4): 777-786.

24. Sharif Y, Sadeghi O, Dorosty A, Siassi F, Jalali M, et al. (2020) Association of vitamin D, retinol and zinc deficiencies with stunting in toddlers: findings from a national study in Iran. Public Health 181: 1-7.

25. Sheoran P, Grewal S, Kumari S, Goel S (2021) Enhancement of growth and yield, leaching reduction in Triticum aestivum using biogenic synthesized zinc oxide nanofertilizer. J B \& Biotechnology A 32: 101938.

26. Holzwarth U, Gibson N (2011) The Scherrer equation versus the'DebyeScherrer equation. Nature Nanotechnology 6(9): 534-534.

27. Koch M, Winkelmann MK, Hasler M, Pawelzik E, Naumann M (2020) Root growth in light of changing magnesium distribution and transport between source and sink tissues in potato (Solanum tuberosum L.). 10(1): 1-14. 
28. Ghidan AY, Kahlel AM (2020) Effect of nanotechnology liquid fertilizers on yield and nitrogenous compounds of broad bean (Vicia faba 1.) Fresenius Environmental Bulletin 29(6): 41244128.

29. Reta D (2020) Biosynthesis of Co304-Zno Nanocomposite Material Using Waste Extract of Potato And Banana Fruits Peel For Antibacterial Application. ASTU.

\section{ISSN: 2574-1241}

DOI: 10.26717/BJSTR.2021.39.006351

Noor Hassan. Biomed J Sci \& Tech Res

(C) (P) This work is licensed under Creative

Submission Link: https://biomedres.us/submit-manuscript.php
30. Mahmood S, Ashfaq UA (2015) Dengue NS5 global consensus sequence development to find conserved region for antiviral drug development. Asian Pacific Journal of Tropical Medicine.

31. Sabir S, Zahoor MA, Waseem M, Siddique MH, Shafique M, et al. (2020) Biosynthesis of ZnO Nanoparticles Using Bacillus Subtilis: Characterization and Nutritive Significance for Promoting Plant Growth in Zea mays L 18(3): 1559325820958911.

$\begin{array}{ll}\text { BIOMEDICAL } & \text { Assets of Publishing with us } \\ \text { RESEARCHES } & \text { - Global archiving of articles } \\ \text { - Immediate, unrestricted online access }\end{array}$

